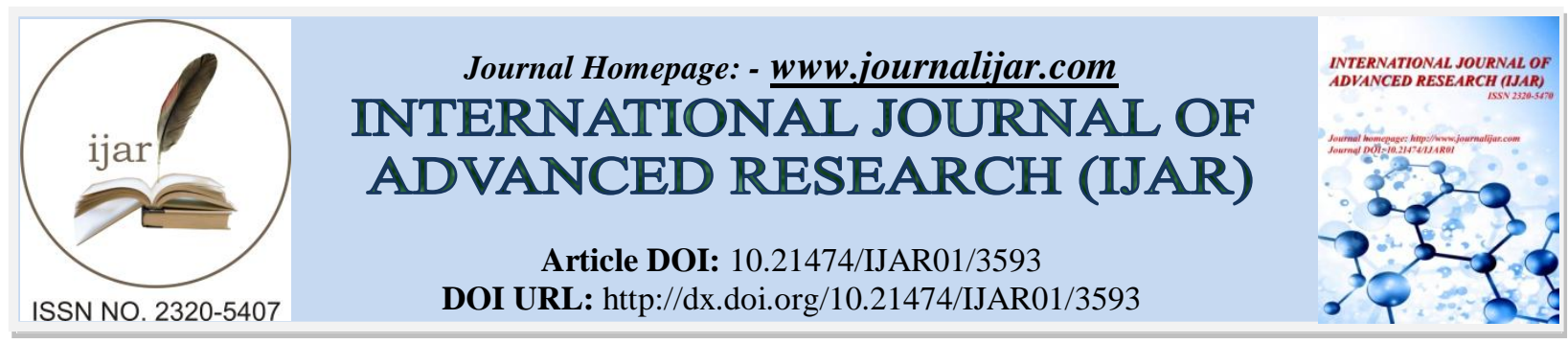

RESEARCH ARTICLE

\title{
AMELIORATING EFFECTS OF TOMATO PUREE AGAINST ARSENIC INDUCED ALTERATION IN OVARY OF SWISS ALBINO MICE.
}

Suman Sharma, "Charanjit Kaur and Anjali Singh Gill.

Department of Zoology \& Environmental Sciences, Punjabi university, Patiala-147002, India.

\section{Manuscript Info}

Manuscript History

Received: 05 January 2017

Final Accepted: 05 February 2017

Published: March 2017

Key words:-

Arsenic (As), tomato puree, ovary and follicle.

\begin{abstract}
Arsenic compound are known to induce toxicity in mammalian system. However reproductive toxicity is comparatively less expedited. Arsenic has a long environmental persistence and never loses its toxic potential. Arsenic affects the reproductive systems of female Swiss mice. In the present study, toxic effects of arsenic are observed on histopathology of ovary studied after adssssssministration of low ( $1 \mathrm{mg} / \mathrm{kg}$ body weight) dose of arsenic trioxide to the Swiss albino mice; along with this tomato puree on arsenic induced toxicity has also been examined. A significant weight loss of ovary was also observed. Moreover, arsenic was also responsible for ovarian follicular degeneration and vacuolization in follicular cells. The results of the present study indicated a marked effect of recovery of the follicle cells of the ovary after exposure to tomato puree with higher dose as it was dose dependent.
\end{abstract}

Copy Right, IJAR, 2017,. All rights reserved.

\section{Introduction:-}

Arsenic in drinking water is one of the top most environmental threats worldwide as it is associated with numerous diseases (Tapio and Groshe, 2006). Environmentally relevant forms of arsenic are inorganic and organic existing in the trivalent or pentavalent state (ASTDR 2007b). Presently, due to enhanced human activities like mining, smelting, coal combustion, etc., the level of arsenic has crossed its permissible limit (Sharma and Singh, 2016) and Chronic intake of arsenic is strongly associated with an increased risk of skin, lung, liver and other cancers, type 2 diabetes, cardiovascular diseases, neurological, cognitive defects, reproductive and developmental problems (Kargas et al., 2002; Prozialerk et al., 2008; Walker et al. 2009). But recently arsenic intoxication in experimental animals has been associated with hepatic tumors (Waalkes et al., 2003), inhibition of testicular steroidogenic function (Sarkar et al., 1991) and spermatogenesis (Sukla and Pandey, 1984) as well as with severe metabolic disorders such as diabetes in humans (Longnecker and Daniels, 2001; Tseng et al., 2002). Long term exposure of arsenic is associated with abortion, low birth weight and reduced lactation (Donald et al., 1995) as well as with embryonic cells toxicity in vitro (Lee et al., 1985). Though, there is scanty literature on the effect of arsenic on ovarian steroidogenic functions, particularly at the dose levels occurring in drinking water in wide areas of India and in other countries where this trace element is present in the range above the admissible limit of 0.01 ppm, (Rahman et al., 2003). Chattopadhyay et al., (1999) considered arsenic to be responsible for the inhibition of ovarian steroidogenesis and as an elevator of adrenocortical steroidogenesis (Ghosh et al., 1999) even when the level of arsenic was within the range in drinking water of West Bengal.

Corresponding Author:- Charanjit Kaur.

Address:- Department of Zoology \& Environmental Sciences, Punjabi university, Patiala-147002, India. 
Chemotherapeutic drugs are effective against cancer cells because they are designed to interfere with rapidly dividing cells. Many chemotherapeutic agents induce the production of free radicals. These free radicals can be bound and detoxified by antioxidant compounds such as lycopene (Sahin, et al., 2010). Lycopene accumulates in relatively few tissues and is found in ripe tomato fruit, watermelon and pink grapefruit giving them a characteristic red pigmentation. Tomatoes and processed tomato products such as juice, ketchup, paste, sauce and soup all are good sources of lycopene and may account for over $85 \%$ of dietary lycopene in the North American diet. Lycopene is considered as cardioprotective and anticarcinogenic (Chen et al., 2007). The lycopene content of tomatoes varies with the variety and increases with fruit ripening. Several studies (Bohm et al., 1995; Lu et al., 1995; Dimascio et al., 1989) have indicated that lycopene is an effective antioxidant and free radical scavenger.The present work is aimed to evaluate the protective role of tomato puree on arsenic induced toxicity in ovaries of albino mice.

\section{Materials And Methods:-}

Animal selection and care:-

Female Swiss albino mice having weight 20-30g were procured from CENTRAL RESEARCH INSTITUTE, KASAULI and DISTRICT SOLAN (H.P.). The present research work has been carried out with the permission of Institutional Ethical Committee (107/99/CPCSEA/2013-02).

They were kept and acclimatized to laboratory conditions for 2 weeks under optimal condition of light and temperature. The animals were given standard mice feed and ad libitum access to R.O water. The animals were handled with humane care in accordance with National Institute of Health guidelines.

Chemicals: - The Arsenic trioxide was obtained from QUALIKEMS FINE CHEMICAL PVT. LTD., NEW DELHI. Its stock solution was prepared by dissolving $1.32 \mathrm{~g}$ of $\mathrm{As}_{2} \mathrm{O}_{3}$ and $4 \mathrm{~g}$ of $\mathrm{NaOH}$ in one litre of distilled water $(1 \mathrm{ml}$ of stock solution contained $1 \mathrm{mg}$ of As) and was administered intraperitoneally to mice. Tomato puree marketed by KISSAN HINDUSTAN UNILEVER PVT. LTD. MUMBAI was used as a source of lycopene. It contained 36.8\% tomato paste.

Experimental design: - Mice were divided into following groups:

Group I- Control animals were given equal volume of distilled water only.

Group II- Albino mice were administered arsenic trioxide at a dose of $1 \mathrm{mg} / \mathrm{kg}$ body weight (b.wt.) intraperitoneally (i.p).

Group III- Mice were injected an acute dose of $1 \mathrm{mg} / \mathrm{kg}$ b.wt. of arsenic trioxide i.p. followed by a daily dose of $20 \mathrm{mg} / \mathrm{kg}$ b.wt. of lycopene for 15 days.

Group IV- Mice were injected an acute dose of $1 \mathrm{mg} / \mathrm{kg}$ b.wt. of arsenic trioxide i.p. followed by a daily dose of $40 \mathrm{mg} / \mathrm{kg}$ b.wt. of lycopene for 15 days.

Autopsies from each group were done on 15 days post treatment. Ovaries were removed, freed of adipose tissue, blotted dry so as to remove blood and were weighed separately.

\section{Histopathological studies:-}

The ovaries were fixed in alcoholic Bouin's fixative and embedded in paraffin wax $\left(58-60^{\circ} \mathrm{C}\right)$ and the sections were cut at 5-7 $\mu$ thick sections were stained with Heamatoxylin-eosin stains.

Statistical analysis: - Data were subjected to Student's $t$ - test is used to compare the control group vs. treated (arsenic) group and antioxidant treated groups.

\section{Results And Discussion:-}

Heavy metals toxicity is a worldwide problem which adversely affects the growth, health, reproductive performance and life span of living organisms (Dhir, 2011). The present study showed a histopathological alterations in ovary of arsenic treated mice were in the form of ovarian follicular degeneration, vacuolization in granulosa cells, loss of uniformity in granulosa cell layer. Chattopadhyay et al., (2003) suggested that As influences hypothalamic pituitary ovarian axis which leads to deficiency in secretion of growth hormone and hence reduction in body weight. Similarly Chattopadhyay et al., (2003) observed ovarian follicular and uterine cell degeneration which was also accompanied by decrease in dopamine levels in the midbrain and diencephalon as well as increased arsenic levels in ovaries, uterus and plasma. Low dopamine levels could decrease gonadotrophin synthesis and secretion. Thus, it attributes to decrease in the number of healthy follicles and increase in the number of apoptotic follicles. The authors suggested that uterine cells degeneration may be due to low ovarian estradiol after arsenic treatment. 


\section{Histological changes in Ovary:-}

The histopathological alterations observed in ovary of arsenic treated mice were in the form of ovarian follicular degeneration, vacuolization in granulosa cells, loss of uniformity in granulosa cell layer loose germinal layer, hyperaemia in medulla and vacuolization in germinal epithelium cells, (Fig.2,6,8) and degenerative changes in the oocyte and reduction in the secondary and graafian oocytes along with an increase in the number of atretic oocytes These findings are supported by the results of Chadhopadhay et al., (2003); Islam et al., (2011) and Dezfouli et al., (2014).

Moreover, it is shown that As is responsible for vacuolization, atrophy and hyperaemia in the medulla along with the decrease in the number of follicles (Jhala et al., 2004; Dezfouli et al., 2014).

Estrogen plays a critical role in regulating the sex organs as well as sex gonadal development. This implies a direact impact on the growth of ovary cells, particular folliculogensis. Furthermore, estrogen elevates the effects of FSH on granulosa cells (Hegele-Hartung et al., 2003) and in this way performs an important role in follicular development. Arsenic reduces the level of estrogen and as an endocrine disruptor can cause ovarin follicular degeneration (Dezfouli et al., 2014).

In the present study, the ovary of TP (20mg) treated mice showed normal histology as compared to arsenic treated mice (Fig 3.). Fig.9 depicted moderate signs of protection as primary follicles showed vacuolization in granulosa cells the number of primary follicles was observed to be more as compared to arsenic treated mice. Group IV As depicted mice co-administration with $40 \mathrm{mg} / \mathrm{kg}$ b.wt. of TP showed a great protection to the ovary against arsenic toxicity. The graffian follicles as well as germinal epithelial layer retained their original shape, structure and thecal layers were also properly discernible (Fig. 4,10).

The existence of LH (Luteinizing harmone) receptor sites in granulosa cell membrane is induced by FSH (Follicle stimulating harmone) that prepares the graafian follicles for a preovulatory LH surge. Furthermore, induction of LH receptors by FSH is necessary for interactions between granulosa cells, which is important in cell differentiation. It is also believed that estrogen enhances the effects of FSH on gene expression in granulosa cells (Erickson et al., 1979). As granulosa cells play important role in development and maturation of oocytes, the dysfunction of granulosa cells may lead to disorder of folliculogenesis and steroidogenesis (Lan et al., 2013). It has been demonstrated that LH stimulates follicular maturation and induces follicular atresia. Sharma et al., (2012) recently suggested that LH is also a stimulant for early stages of follicular growth. Heavy metals not only exerted inhibitory effect on follicular growth but also stimulated the atretic follicle formation (Tajima et al., 2007; Mori et al., 2009).

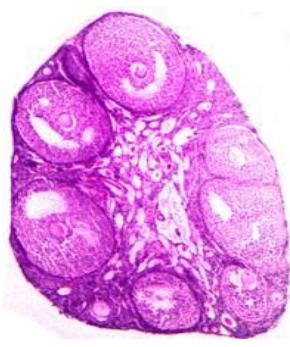

Fig.1

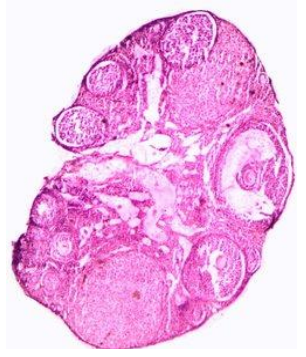

Fig.2

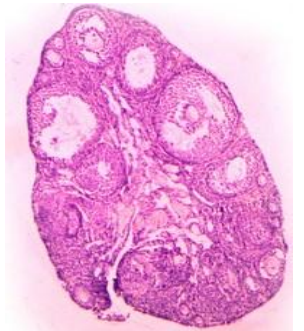

Fig.3

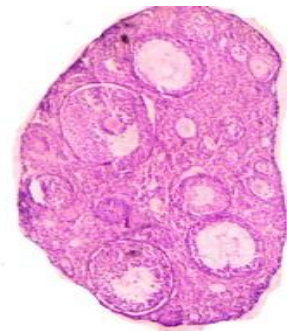

Fig.4

Hematoxylin and eosin-stained sections of mice ovary (40x): Fig. 1 Normal control mice ovary: normal medulla matures graafian follicles and normal surface epithelium. Fig. 2 arsenic $(1 \mathrm{mg})$ - treated mice ovary: atretic follicles. Fig.3 As 1mg+ TP 20mg — treated mice ovary: vacuolization in granulosa cells. Fig.4 As 1mg+ TP40 mg - treated mice ovary: almost normal graafian follicle with normal architecture of medulla.

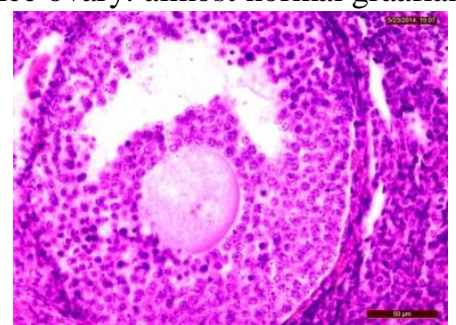

Fig.5

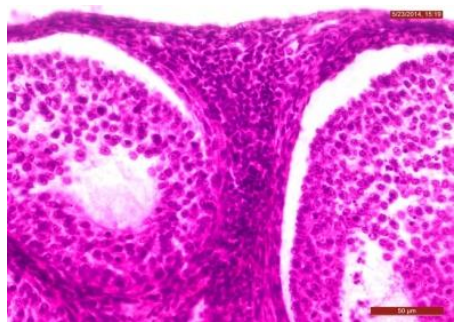

Fig.6

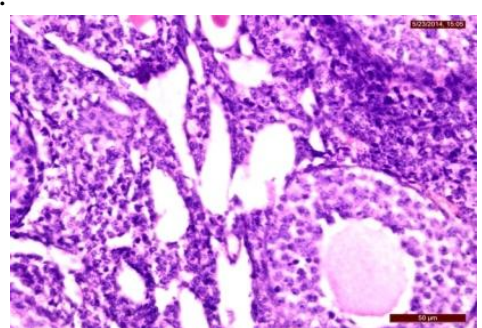

Fig.7 


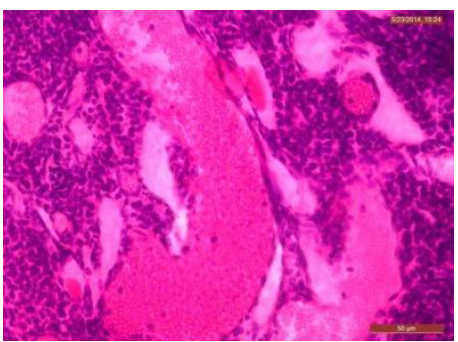

Fig.8

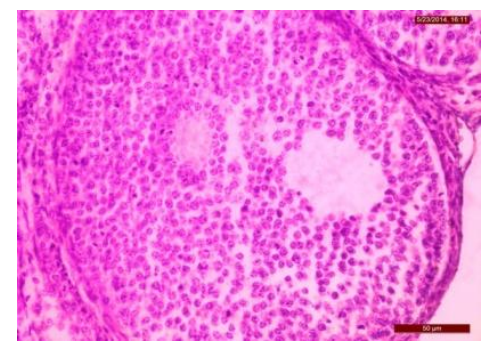

Fig.9

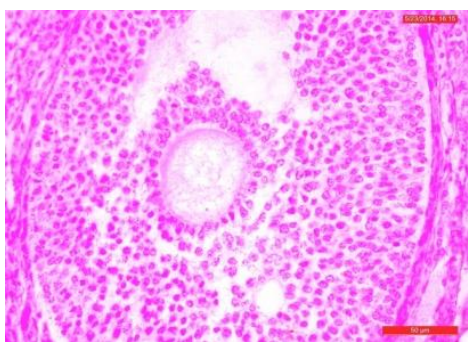

Fig.10

Hematoxylin and eosin-stained sections of mice ovary (400x) Fig.5 Normal control mice ovary: normal cells of graafian follicle, compact layer of granulosa cells. Fig.6 Arsenic $(1 \mathrm{mg} / \mathrm{kg})$ - treated mice ovary: vacuolization loosening of granulosa cells, vacuolization in germinal epithelium cells. Fig.7 Normal control mice ovary: normal architecture of medulla. Fig.8 Arsenic (1mg/kg) - treated mice: hyperaemia in medulla. Fig.9 As $1 \mathrm{mg}+\mathrm{TP} 20 \mathrm{mg}-$ treated mice ovary: vacuolization in granulosa cells, the layer is not uniformly compact (400×). Fig. 10 As $1 \mathrm{mg}+$ TP 40mg - treated mice ovary: compact layer of granulosa cells, oocyte and almost normal architecture of theca externa.

\section{Conclusion:-}

There are many evidences supporting the antitoxic and anticancer action of tomato puree. The results of the present study demonstrates that arsenic induced histomorphological and oxidative stress is responsible for promoting deleterious effects of arsenic in the ovaries, but tomato supplementation (tomato puree) which is considered as one of the most potent antioxidants among dietary carotenoids showed very promising and encouraging ameliorative effects on arsenic induced oxidative stress in female reproductive organs of swiss albino mice.

\section{Acknowledgement:-}

The authors gratefully acknowledge the facilities provided by Department of Zoology and Environmental Sciences, Punjabi University, Patiala to pursue the research work.

\section{References:-}

1. ATSDR. (2007b): Toxicological Profile for Arsenic Agency for Toxic Substances and Disease Registry, U.S. Department of Health and Human Services, Atlanta, GA. Available at: http://www.atsdr.cdc.gov/ToxPro files/tp2.pdf. Accessed July 27, 2011.

2. Bohm, F., Tinkler, J.H. and Truscott, T.G. (1995): Carotenoids protect against cell membrane damage by the nitrogen dioxide radical. Journal of Natural Medicine, 1: 98-99.

3. Chen, Y., Jungsuwadee, P., Vore, M., Butterfield, D.A. and Clair, D.K. (2007): Collateral damage in cancer chemotherapy: oxidative stress in non targeted tissues. Molecular Intervention, 7: 147-156.

4. Chattopadhyay, S., Ghosh, S.P., Ghosh, D. and Debnath, J. (2003): Effect of dietary co-administration of sodium selenite on sodium arsenite-induced ovarian and uterine disorders in mature Albino rats. Toxicological Sciences, 75(2): 412-422.

5. Chattopadhyay, S., Ghosh, S., Chaki, S., Debnath, J., and Ghosh, D. (1999): Effect of sodium sodium arsenite on plasma levels of gonadotrophins and ovarian steroidogenesis in mature albino rats: Duration dependent response. Journal of Toxicological Sciences, 24: 425-431.

6. Dezfouli, M.G.Z., Eissazadeh, S. and Zade, S.M.A.S. (2014): Histological and histometrical study of the protective role of $\alpha$-tocopherol against sodium arsenite toxicity in rat ovaries. Microscopic Microanalysis, 1-13.

7. Dhir, V. (2011): Study of cancer causing carcinogens like heavy metal ions $\left(\mathrm{Cu}^{2}+, \mathrm{Cd}^{2}+\& \mathrm{~Pb}^{2}+\right)$ on the organs of female rats and also evaluate the critical effects on the progenies of pregnant female rats. International Journal of Pharmaceutical and Clinical Science, 1(2): 9-18.

8. Dimascio, P., Kaiser, S. and Sies, H. (1989): Lycopene as the most effective biological carotenoid singlet oxygen quencher. Archives of Biochemistry and Biophysics, 274: 532-538.

9. Donald, M.C., Edwards, R.A., and Greenhalgh, J.F.D. (1995): Minerals in animal nutrition (Eds.), Longman ELBS, England, pp.127-136.

10. Erickson, G.F., Wang, C. and Hsueh, A.J.W. (1979): FSH induction of functional LH receptors in granulosa cells cultured in a chemically defined medium. Nature, 279: 336-338.

11. Ghosh, D., Chattopadhyay, S. and Debnath, J. (1999): Effect of sodium arsenite on adrenocortical activity in immature female rats: Evidence of dose dependent response. Journal of Environmental Sciences, 11: 419-422. 
12. Hegele-Hartung, C., Siebel, P., Peters, O., Kosemund, D., Muller, G., Hillisch, A., Walter, A., Kraetzschmar, J. and Fritzemeier, K.H. (2003): Impact of isotypeselective estrogen receptor agonists on ovarian function. Proceedings of the National Academy of Sciences, 101(14): 5129-5134.

13. Islam, M.T., Parvin, S., Pervin, M., Bari, A.S.M. and Khan, M.A.H.N.A. (2011): Effects Of chronic arsenic toxicity on the haematology and histoarchitecture of female reproductive system of black Bengal goat. Bangladesh Society for Veterinary Medicine, 9(1): 59-66.

14. Jhala, D.D., Nair, S.B. and Chinoya, N.J. (2004): Reversible toxicity of fluoride and arsenic in ovary of mice. Fluoride and arsenic reversal in mice ovary, 37(2): 71-79.

15. Kargas, M.R., Stukel, T.A. and Tosteson, T.D. (2002): Assesment of cancer risk and environmental levels of arsenic in New Hampshire. International Journal of Hygiene and Environmental Health, 205(1): 85-94.

16. Lan, C.W., Chen, M.J., Jan, P.S., Chen, H.F. and Ho, H.N. (2013): Differentiation of human embryonic stem cells in to functional ovarian granulosa- like cells. Journal of Clinical Endocrinology and Metabolism, 98(9): 3713-3723.

17. Lee, T.C., Oshimura, M. and Barrett, J.C. (1985): Comparison of arsenic- induced cell transformation, cytotoxicity, mutation and cytogenetic effects in Syrian hamster embryo cells in culture. Carcinogenesis, 6: $1421-1426$.

18. Longnecker, M.P. and Daniels, J.L. (2001): Environmental contaminants as etiologic factors for diabetes. Environmental Health Perspectives, 6: 871-876.

19. Lu, Y., Etoh, H. and Watanabe, N. (1995): New carotenoid, hydrogen peroxide oxidation products from lycopene. Bioscience, Biotechnology and Biochemistry, 59: 2153-2155.

20. Mori, T., Nonogauchi, K., Watanabe, H., Ishikawa, H., Tamura, I. and Kinoshita, K. (2009): Morphogenesis of polycystic ovaries as assessed by pituitary ovarian androgenic function. Reproductive Biomedicine Online, 18: 635-643.

21. Prozialeck, W.C., Edwards, J.R., Nebert D.W., Woods, J.M., Barchowsky, A. and Atchison, W.D. (2008): The vascular system as a target of metal toxicity. Toxicological Sciences, 102(2): 207-218.

22. Rahman, A., Vahter, M., Ekstro, E.C., Rahman, M., Mustafa, A.H.M.G., Wahed, M.A., Yunus, M. and Persson, L.A. (2003): Association of Arsenic Exposure during Pregnancy with Fetal Loss and Infant Death. American Journal of Epidemiology, 165(12): 1389-1396.

23. Sahin, K., Sahin, N. and Kucuk, O. (2010): Lycopene and Chemotherapy Toxicity. Nutrition and Cancer, 62(7): 988-995.

24. Sakar, M., Biswas, N.M. and Ghosh. (1991): Effect of testicular $\Delta^{53} \beta, 17 \beta$ HSD activity in albino rat dose and duration dependent responses. Medical Science Research, 19: 789- 790.

25. Sharma, V. and Singh, R. (2016): Haematological and immunological response of Achyranthes aspera leaf and root extracts in arsenic-intoxicated female mice (Mus musculus). Research communications, 110(4): 701-708.

26. Sukla, J.P. and Pandey, K. (1984): Impaired spermatogenesis in arsenic- treated fresh water fish Colisa fasciatus (B1 and Sch). Toxicology Letters, 21: 191-195.

27. Tajima, K., Orisaka, M., Mori, T. and Kotsuji, F. (2007): Ovarian theca cells in follicular function. Reproductive Biomedicine Online, 15(4): 591-609.

28. Tapio, S. and Grosche, B. (2006): Arsenic in the aetiology of cancer. Mutation Research, 612: $215-246$.

29. Tseng, C.H., Tseng, C.P., Chiou, H.Y., Hsueh, Y.M., Chong, C.K. and Chen, C.J. (2002): Epidemiologic evidence of diabetogenic effect of arsenic. Toxicology Letters, 133: 69-76.

30. Waalkes, M.P., Ward, J.M. and Diwan, B.A. (2003): Induction of tumors of the liver, lung, ovary and adrenal in adult mice after brief maternal gestational exposure to inorganic arsenic: promotional effects of postnatal phorbol ester exposure on hepatic and pulmonary, but not dermal cancers. Carcinogenesis, 25(1): 133-141.

31. Walker, M. and Fosbury, D. (2009): Arsenic trioxide and tungsten in Neveda Country's private water supplies. Journal of Water Health, 7(2): 293-301. 